\section{Digitalidade e}

\section{narrativa}

\section{audiovisual: uma}

\section{relação complexa}

\section{RESUMO}

Este artigo pretende estabelecer uma certa hierarquia das transformações no campo audiovisual, distinguindo o que altera de modo significativo a concepção e a fruição das obras e fazendo o observador alterar seu próprio posto de observação (o que não passa muitas vezes de simples ilusão estimulada pelo mercado). 0 foco do artigo está no campo audiovisual narrativo, isto é, sobre como contar estórias com imagens e sons sincronizados frente ao impacto das novas tecnologias.

\section{ABSTRACT \\ This article tries to establish a kind of hierarchy of trans- formations taking place in our contemporary audiovisual field. It is focused on the audiovisual narrative, that is, on how to tell stories, with sincronized images and sounds, in face of the latest technological advances. \\ PALAVRAS-CHAVE / KEY-WORDS \\ - Linguagem (Language) \\ - Audiovisual (Audiovisual) \\ - Imagem (Image)}

Carlos Gerbase

Mestrando/PUCRS

\section{Introdução}

TRANSFORMAÇÕES SEMPRE HÁ. Se vivêssemos num mundo sem mudança, o observador estaria condenado a perceber sempre o mesmo, sem nada a relatar de diferente, constituindo-se num não-observador e, portanto, num não-ser. Não é nossa intenção neste artigo, nem de longe, pregar uma imobilidade da tecnologia ou da linguagem do audiovisual. É claro que elas estão em mutação desde que foram criadas e continuarão se metamorfoseando enquanto forem vivas e observáveis. Mas dizer que tudo se transforma não nos dá o direito de dizer que todas as transformações são igualmente importantes, a ponto de demarcarem novos territórios de observação e estudo, novos paradigmas para quem produz, novas percepções para quem consome.

Pretendemos, isto sim, estabelecer uma espécie de hierarquia das transformações no campo do audiovisual, de modo a distinguir o que altera de modo significativo a concepção e a fruição das obras, fazendo o observador alterar seu próprio posto de observação (sob o risco de não acompanhar mais devidamente o que observa), e o que não passa de ilusão transformacional, muitas vezes estimulada pelo mercado, que agrega valor financeiro a uma mudança sempre que ela pode aumentar o lucro dos fabricantes de tecnologia e de produtos audiovisuais. Esta ilusão, que promove alterações cosméticas a revoluções destruidoras, também é costumeiramente validada por estudos acadêmicos, que anseiam em reconstruir o mundo a cada vinte minutos, contanto que o autor possa aparecer na foto da inauguração da nova obra. 
As transformações que as tecnologias digitais trouxeram para a vida humana são inegáveis, principalmente no setor da comunicação audiovisual. Este cenário de mudança está sendo estudado em todo o mundo, tanto em seus aspectos pragmáticos (como fazer melhores produtos audiovisuais) como em suas implicações estéticas e filosóficas (o que estes novos produtos audiovisuais têm a oferecer de novo na fruição do mundo).

Este estudo, no entanto, não pode se deixar levar nem pelas regras do marketing, ditadas pelos fabricantes dos equipamentos, nem pelas elucubrações exageradas de teóricos ansiosos em descrever renascimentos a cada nova função disponível no teclado do computador.

Nosso esforço é de parar e pensar um pouco, observando com mais calma o rastro do furacão digital, de modo a distinguir o que ele realmente destrói (e que terá de ser reconstruído) e o que ele apenas levanta aos ares, dá uma sacudida e devolve ao chão (e que continuará sendo usado, pelo menos até a passagem do próximo furacão).

Cabe ainda uma advertência: nossa preocupação está centrada no campo audiovisual narrativo, isto é, no impacto das novas tecnologias sobre o ato de contar histórias com imagens e sons sincronizados, considerando "histórias" num sentido bem amplo, que abrange tanto a ficção quanto a não-ficção (documentários).

Sendo assim, a tradição a ser quebrada está nos domínios do cinema (uso de película com sais de prata), da televisão (codificação eletrônica da imagem e sua transmissão a distância) e do vídeo (armazenagem e posterior tratamento da imagem através da edição).

Também consideramos importante a circunstância em que esta história é recebida, pois uma sala pública e escura, uma TV no ambiente doméstico ou o monitor de um computador proporcionam espetáculos de diferentes qualidades, independente do suporte original do produto audiovisual que está sendo veiculado.

Parente e a transformação geral

Muitos dos estudos acadêmicos sobre as influências da tecnologia digital na imagem estão num patamar teórico (sem fornecer exemplos de qualquer tipo ao leitor), ou simplesmente desconsideram a narrativa audiovisual, permanecendo nos campos da imagem estática (desenho, pintura, fotografia, computação gráfica) e da imagem em movimento sem compromisso narrativo tradicional (experiências em videoarte, animações muito curtas ou circulares realizadas por computador, efeitos variados de tratamento e transição de imagem, como "morphing", e a miríade de manipulações que uma ilha de edição digital permite). Embora esse tipo de reflexão não incida diretamente sobre nosso objeto de estudo, faremos a seguir um breve apanhado dos pensamentos de alguns autores, para demonstrar como a digitalidade é considerada uma verdadeira revolução na formas de representação da imagem.

André Parente (1993: 27) faz uma advertência radical:

"Não podemos negar que os processos eletrônicos digitais provocarão uma transformação geral, completa, irreversível, de todas as fases de elaboração de uma imagem. Chegará um dia onde tudo será digitalizado e colocado em memória, e o suporte da imagem desaparecerá, tanto quanto o seu valor de revelação e referência. Ignorar ou fingir ignorar as modificações no sistema de informação-comunicação com o advento dos processos de digitalização do sinal eletrônico significa ter uma concepção retrógrada dos processos tecnológicos e uma visão negativa da história."

Não queremos ignorar, nem fingir 
ignorar, o impacto das tecnologias digitais, mas Parente parece ultrapassar os limites do bom senso em suas observações da revolução digital. Se a transformação será "geral, completa e irreversível, de todas as fases de elaboração da imagem", ele está predizendo, entre outras coisas, o fim do uso da câmara escura como instrumento óptico fundamental para a captação da imagem em movimento no cinema, na televisão ou no vídeo. Seria quebrada uma tradição de muitos séculos, de origem bem anterior ao invento da fotografia, que tem permitido à humanidade enviar uma fração do mundo real e tridimensional para dentro de uma caixa (a câmara escura), na forma de uma imagem bidimensional. Parente, ao que tudo indica, considera que será possível, em curto espaço de tempo, substituir a velha seleção dos raios de luz da objetiva (ou de um simples "furinho" na parede de câmara) por algum outro mecanismo de síntese da imagem.

Cabem então algumas perguntas: que mecanismo é esse? Baseado em que princípios físicos ele funcionará? Como será sua organização interna? Perguntas sem resposta em 1993, ano em que o texto de Parente foi escrito, e em 2000, ano em que escrevemos. Qualquer tentativa de apresentar a tecnologia da síntese numérica de imagens permitida pelo computador, no campo da computação gráfica e suas inúmeras derivações, como substituição completa da câmara escura não encontra qualquer sustentação na realidade. $\mathrm{O}$ que acontece - e continuará, a nosso ver, acontecendo - é o gradual estabelecimento de três campos distintos na produção de imagens para espetáculos audiovisuais narrativos:

\section{Primeiro campo - produtos} audiovisuais narrativos cujas imagens são inteiramente originadas pelo mecanismo da câmara escura, isto é, câmaras de cinema, de televisão e de vídeo. Não importa que o suporte dessas imagens seja analógico (filme e vídeo tradicional) ou digital. Mas é importante que, nas demais etapas de realização, não aconteçam transformações radicais na estrutura dessas imagens. Nesse campo ainda se encontra a grande maioria dos filmes cinematográficos, mesmo aqueles que, em sua finalização, usam amplamente os recursos da edição digital de som e de imagem. Em outras palavras: os filmes da era digital podem continuar a ser feitos quase exatamente como eram feitos na era das moviolas, das fitas magnéticas perfuradas e da mixagem mecânica (que envolvia uma parede inteira de gravadores de som sincronizados).

\section{Segundo campo - produtos} audiovisuais narrativos cujas imagens não são geradas, em momento algum, pelo mecanismo da câmara escura. Mais uma vez, nessa classificação que propomos, pouco importa que o suporte dessa imagem seja analógico (desenho animado tradicional, feito no papel) ou digital (computações gráficas de qualquer tipo, hoje existentes ou que venham a ser criadas). Nesse campo estão os filmes de cinema de desenho animado; todos os desenhos animados que ocupam a televisão e o mercado de vídeo; a grande maioria dos videogames e jogos de computador com alguma preocupação narrativa; e uma infinidade de outros produtos, presentes nos mais diversos suportes, antigos, contemporâneos ou que venham a ser criados.

\section{Terceiro campo - produtos} audiovisuais que combinam, de alguma forma, imagens originadas pelo mecanismo da câmara escura e imagens sintetizadas por computador. Essa combinação, hoje, já é feita quase que exclusivamente através de equipamentos digitais, mas o suporte em que elas chegam ao público ainda pode ser analógico (os filmes que passam no cinema, as fitas VHS dos videoclubes e a TV tradicional) ou digital (internet, DVD, televisão digital). Nesse campo, em expansão avassaladora, podem ser 
colocados produtos audiovisuais narrativos de " $n$ " tipos diferentes. Poderíamos partir de filmes cinematográficos de Hollywood, como Star Wars: A ameaça fantasma, em que não há um só fotograma que não tenha recebido tratamento digital, até chegar em produções caseiras ou vídeos de casamento, editados em ilhas digitais cheias de efeitos ou dentro de computador es.

Ora, se para Parente e para muitos outros teóricos a revolução digital trará uma transformação "geral, completa e irreversível de todas as fases de elaboração de uma imagem", temos que considerar o seguinte cenário: eliminação completa do primeiro e do terceiro campos de produção audiovisual narrativa (que usam a câmara escura) e a ampliação (até chegar ao domínio absoluto) do segundo campo. Alguém, em sã consciência, pode admitir esse cenário num futuro próximo? Ou melhor: alguém pode desejar esse cenário, que, em vez de ampliar as possibilidades narrativas, destrói dois campos ainda férteis, capazes de gerar obras de arte de inegáveis qualidades estéticas?

Por que o cinema e a televisão prescindiriam de um ator-ser humano, com as emoções de seu rosto captadas facilmente, fração de segundo a fração de segundo, por uma câmara, em função da possibilidade de colocar, com imensas dificuldades, essas mesmas emoções sobre o rosto de um ator simulado numericamente por um computador? Parente está defendendo não uma revolução libertadora, e sim uma contra-revolução reacionária, em que a tecnologia é um valor em si mesmo, capaz de negar formas de manifestação artística ainda férteis em função de uma pretensa onipotência gerativa das imagens digitais. Não há onipotência do cotidiano dos homens, a não ser a onipotência artificial gerada por uma ditadura.

Quando Parente fala em "ter uma concepção retrógrada dos processos tecnológicos e uma visão negativa da história", está falando dele mesmo.
Por que não podemos ver as novas tecnologias digitais como novas e poderosas ferramentas - o que elas são, quase sempre - em vez de totens pósmodernos, que exigem adoração absoluta e a incineração imediata de todos os outros ídolos? Por que negar a convivência de tecnologias, de formas de representação, de estratégias de produção, de diferentes visões de mundo? Não se trata de negar a influência da digitalidade - que existe, é importante, e talvez, a longo prazo, decisiva - e sim de medir o que é influência real e o que não passa de acréscimo quase supérfluo numa tradição audiovisual importante e que ainda tem muito a oferecer.

É claro que Parente, assim como muitos outros teóricos da digitalidade, fazem questão de exagerar suas conclusões para que estas sejam espetaculares e chamem a atenção de seus leitores. Mas isso costuma gerar confusão, em vez de esclarecimento. Vejamos o que Parente fala da televisão digital (em 1993):

"A televisão digital (ADTV) é o objetivo último das mutações tecnológicas projetadas hoje no campo audiovisual. As vantagens da televisão digital são imensas: maior resolução e compacidade dos circuitos, unificação dos sistemas de transmissão de cores, durabilidade, interação com os sistemas informatizados. A imagem digital torna simples algumas operações impensáveis até há pouco tempo em sistemas do tipo fotomecânico: alteração das cores, das texturas, dos movimentos e da perspectiva, inserção de imagens sobre porções e cores desejadas de uma imagem, refocagem e reenquadramento da imagem, mesmo após a captação da mesma, entre outras possibilidades. Ressaltamos ainda que, com a televisão digital, as diferentes fases da produção audiovisual - pré-produção, produção 
e finalização - serão completamente reformuladas. A interação da televisão com a informática e a telemática, o fato que teremos um mesmo monitor para televisão, o computador e o telefone, poderá propiciar ao usuário uma programação criativa, ao reintroduzir certos aspectos da subjetividade no processo de comunicação, provocando um novo tipo de socialidade."1

Sete anos depois, constatamos que:

a) a resolução da HDTV (highdefinition TV), transmitida ou não digitalmente (aliás, a resolução de uma imagem não cresce simplesmente por ser digital), ainda é muito inferior à do filme;

b) há uma disputa feroz em torno de padrões de transmissão da TV digital, e é bem possível que, no final das contas, tenhamos a mesma babel da TV analógica;

c) TVs e outros eletrodomésticos duram cada vez menos, não por apresentarem defeitos, e sim porque já saem das lojas superados tecnologicamente por outros eletrodomésticos, em fase de projeto ou até em fabricação;

d) nenhuma interação da TV com sistemas informatizados produziu alterações significativas nas programações audiovisuais do mundo todo, pelo menos nos mercados massivos;

e) não se registraram mudanças estruturais na produção audiovisual narrativa. Continuamos lidando com roteiristas, diretores, diretores de fotografia, produtores, montadores e finalizadores;

f) quando se senta na frente de uma TV (digital ou analógica) para ver um filme ou assistir a um programa de televisão, não queremos reenquadrar, refocar, mudar as cores, alterar a ordem das cenas. Queremos apenas assistir, naquela hora, a um espetáculo audiovisual preparado por alguém, um autor, que vai nos contar uma história;

g) o fato de podermos programar em que horário vamos assistir ao espetáculo, ou que podemos usar um monitor de computador em vez de uma TV tradicional, não muda o espetáculo em si, e sim a circunstância em que o assistimos. E, por enquanto, nenhuma nova circunstância de espetáculo superou uma sala de cinema tradicional, grande, escura, coletiva e com sistema de imagem e som de última geração.

Sempre é bom lembrar que Parente não está falando apenas de processos audiovisuais narrativos, e, portanto, muitas de suas "visões" podem ser hoje comprovadas, parcialmente, na internet e em novos suportes físicos, como o DVD. Mas como ele não tem qualquer cuidado em categorizar as imagens ou relativizar suas profecias, atacamos suas generalizações sem medo de demonstrar uma postura excessivamente crítica. Ou será que uma "geladeira com internet", apresentada na Fenasoft em julho de 2000, é a definitiva prova de que a digitalidade mudou nossas vidas?

Couchot e a nova lógica figurativa

Edmont Couchot é um pouco mais cuidadoso que Parente ao analisar a digitalidade das imagens. Em seu artigo "Da representação à simulação: evolução das técnicas e das artes da figuração", descreve a evolução dos processos de automatização da imagem, primeiro num contexto analógico, depois no domínio digital. Nessa evolução, ele destaca que "as técnicas figurativas não são apenas meios para criar imagens de um tipo específico, são também meios de perceber e de interpretar o mundo". ${ }^{2}$ Até aí, nada a opor. Há, realmente, novas percepções e novas interpretações do mundo na passagem da pintura para a fotografia, e desta para o cinema. Mas o mesmo Couchot (1993) admite que, enquanto se usa a câmara escura, "são idênticos os processos 
morfogenéticos de formação da imagem a partir de uma emanação luminosa; idêntica sua aderência ao real". E ele vai além: considera que a televisão não modificou esse cenário, à medida que mantém "o enquadramento espacial e temporal (automático) da imagem, imposto pelas tecnologias da Representação"(Couchot 1993).

Ao contrário de outros teóricos, que criam um abismo entre a imagem cinematográfica, obtida com sais de prata, e a imagem da TV e do vídeo, obtida em processo eletrônico, Couchot admite que as diferenças técnicas entre os dois veículos, que existem e são consideráveis, são menos relevantes que o mecanismo que estes veículos compartilham: a câmara escura, que traz sua lógica de representação e suas seculares leis de operação.

A revolução, para Couchot, acontece somente com a digitalização da imagem:

"Com as tecnologias numéricas, a lógica figurativa muda radicalmente e com ela o modelo geral de figuração. Ao contrário do que se poderia prever, o pixel, sendo um instrumento de controle total, torna na verdade bem mais difícil a morfogênese da imagem. Enquanto para cada ponto da imagem ótica corresponde um ponto do objeto real, nenhum ponto de qualquer objeto preexistente corresponde ao pixel. O pixel é a expressão visual, materializada na tela, de um cálculo efetuado pelo computador, conforme as instruções de um programa. Se alguma coisa preexiste ao pixel e à imagem é o programa, isto é, linguagens e números, e não mais $o$ real. Eis por que a imagem numérica não representa mais 0 mundo real, ela o simula. Ela o reconstrói, fragmento por fragmento, propondo dele uma visualização numérica que não mantém mais nenhuma relação direta com o real, nem física, nem

\section{energética."(Couchot 1993)}

É grande a confusão deste parágrafo, que começa por um sentido de onipotência da digitalidade semelhante ao de Parente (o pixel como "instrumento de controle total") e termina com uma negação categórica da relação entre a imagem digital e a realidade. Mais uma vez, a culpa da confusão está numa generalização excessiva. Couchot parece estar falando de toda e qualquer imagem, pois advoga uma mudança no "modelo geral de figuração". Portanto, imagens digitais obtidas com o uso da câmara escura (que caracterizamos há pouco como os campos "primeiro" e "terceiro") sofreriam a mesma transformação radical das imagens digitais "puras", isto é, obtidas sem o uso da câmara escura (o nosso "segundo campo"). Contudo, ao dizer que "nenhum ponto de qualquer objeto preexistente corresponde ao pixel", Couchot remete seu raciocínio a um campo mais restrito, porque sabemos que, por exemplo, numa câmara fotográfica digital, há uma correspondência evidente e inegável entre os pixels que formam a imagem digital armazenada na memória da câmara e os pontos dos objetos reais que estão na frente da objetiva da câmara.

Este parece ser, grosso modo, o pecado capital dos comentadores da tecnologia digital: sua incapacidade de distinguir as diferentes formas de atuação da tecnologia numérica no processo de produção de imagens. Mesmo Couchot, que reconhece a câmara escura como pilar da representação e da figuração, esquece dela quando fala da "nova lógica figurativa", e cai na mesma generalização e na mesma adoração irracional de Parente.

Um pouco mais adiante, no mesmo texto, Couchot, já menos emocionado, reconhece, mesmo que confusamente, dois campos distintos, que chama de "técnicas figurativas ópticas" e "técnicas figurativas numéricas". Afirma que ambas são interpretações do mundo, mas as "numéricas" são "acentuadamente teóricas, 
argumentadas, formalizadas, mesmo quando não o são, em numerosos casos, segundo os princípios da lógica formal e das matemáticas". Quem já viu uma criança de três anos desenhando num computador terá dificuldade de perceber onde, neste processo de produção de imagem, está o seu caráter acentuadamente teórico ou argumentado. Ao conduzir o mouse, a criança estará fazendo algo estruturalmente diferente do que faz ao conduzir um lápis de cor? Se está, teríamos que encontrar diferenças fundamentais, ontológicas, entre o desenho "digital" impresso num papel e um desenho "analógico", diretamente realizado sobre este suporte.

$\mathrm{Na}$ qualidade de pai de três crianças que cresceram transitando facilmente entre o computador e as canetas, posso afirmar que não: os padrões se repetem, o estilo de figuração é o mesmo, a capacidade de imitar o real se mantém inalterada. A única observação que elas costumam fazer é que no computador "fica mais fácil colorir", o que é exatamente o que acontece na produção contemporânea de desenhos animados. Há artistas que preferem o papel para desenhar, outros trabalham direto no computador, mas o ato de colorir é sempre realizado digitalmente, porque, havendo um elevado grau de repetição de ações, o computador é muito mais rápido e mais preciso que o ser humano.

Couchot afirma que as técnicas figurativas numéricas

“...substituem o real "bruto", originário - o real que a imagem óptica pretende representar - por um real secundário, refinado, purificado no cadinho dos cálculos e das operações de formalização. Não se trata mais, então, de fazer a imagem representar um real organizado pela superfície do espelho, pelo orifício da câmara escura ou pela varredura da câmara eletrônica. Não se trata mais de figurar o que é visível: tratase de figurar o que é modelizável.
Chega-se, nesse ponto, à nova e fantástica potência da figuração numérica e, simultaneamente, a seus limites, uma vez que a imagem numérica só pode figurar aquilo que é modelizável."(Couchot 1993)

Chega-se, igualmente, ao limite da paciência de qualquer leitor (não digo enciclopédico, mas apenas minimamente informado e crítico). Ao introduzir o conceito de "modelização" Couchot afasta, mais uma vez, a câmara escura do universo digital, mas envereda por um caminho sem saída, ao afirmar que as técnicas digitais não pretendem "figurar o que é visível". De que técnicas Couchot está falando, afinal de contas? Onde estão estas "modelizações" no universo audiovisual dos seres humanos do ano 2000? Serão as belas imagens abstratas geradas por computação gráfica, que vivem exclusivamente em museus e álbuns de arte de luxo, impressos em papel cuchê, de preço proibitivo, ou servindo de cenário para comerciais de cigarros e de carros esportivos?

E estes limites que Couchot aponta? Onde estão, na prática? O que não pode ser modelizável e, portanto, não pode ser figurado digitalmente? Para finalizar, vale destacar um erro grosseiro na seguinte frase de Couchot: "Não se trata mais, então, de fazer a imagem representar um real organizado pela superfície do espelho, pelo orifício da câmara escura ou pela varredura da câmara eletrônica". Couchot coloca em oposição "orifício da câmara escura" e "varredura da câmara eletrônica", quando, na verdade, toda câmara eletrônica possui, necessariamente, uma objetiva, que nada mais é do que um orifício tecnologicamente aprimorado. Só depois que a objetiva forma a imagem ocorre a varredura eletrônica. Talvez Couchot quisesse de referir ao "scanner". Talvez. Sua imprecisão pontual, contudo, é um belo espelho de sua incapacidade de ver a digitalidade em seu verdadeiro contexto complexo, que não nega o "visível" nem o "analógico" (apesar 
de sua relativa capacidade de ultrapassálos), e sim oferece novas e fascinantes possibilidades de produção de imagens. Com seus limites e até com suas lógicas próprias, mas não os limites e lógicas confusamente descritos por Parente e Couchot.

\section{Machado e a inscrição do tempo}

Para muitos, apenas o fato da imagem em movimento do vídeo ser eletrônica é o suficiente para dar-Ihe "status" de nova linguagem. Arlindo Machado (1993) possui um texto chamado "Anamorfoses cronotópicas ou a quarta dimensão da imagem", em que procura estabelecer uma divisão importante entre cinema e vídeo:

"Como já é sabido, as câmeras eletrônicas diferem das câmeras fotográficas e cinematográficas por retalharem as imagens numa seqüência de linhas de retículas, de modo a possibilitar varrê-las por feixes de elétrons e assim convertêlas numa seqüência de impulsos elétricos, que serão, por sua vez, distribuídos através de ondas ou gravados em suporte eletromagnético. Em outras palavras, a imagem eletrônica não consiste em outra coisa que um conjunto de linhas sobrepostas e sucessivas, cada uma delas constituída por um número dado de pontos elementares de cor, que se juntam num quadro para formarem um painel de retículas, à maneira da técnica pictórica do mosaico. (...) Tecnicamente, a imagem eletrônica se resume a um ponto luminoso que corre a tela, enquanto variam sua intensidade e seus valores cromáticos. Isso significa que em cada fração de tempo não existe propriamente uma imagem na tela, mas um único pixel, um ponto elementar de informação de luz. A imagem completa, o quadro videográfico, não existe mais no espaço, mas na duração de uma varredura completa da tela, portanto no tempo. A imagem eletrônica não é mais, como eram todas as imagens anteriores, ocupação da topografia de um quadro, mas a síntese temporal de um conjunto de formas de mutação. ${ }^{3}$

A busca de Machado por uma especificidade da imagem eletrônica é paradoxal: aparentemente, está indo à raiz do problema, está tratando de modificações estruturais, mas, para que essas modificações se evidenciem, esquece o papel do espectador, tratando a questão de um ponto de vista exclusivamente técnico. O que o leva a uma nova afirmativa bombástica (e ao mesmo tempo frágil):

"Na realidade, as câmeras eletrônicas constituem os primeiros dispositivos enunciadores realmente capazes de anotar o tempo em imagens seqüenciais, uma vez que o cinema apenas simula um efeito de duração através de uma sucessão de fotogramas fixos. Isso quer dizer que a real cinematografia, levando-se em consideração a etimologia da palavra (do grego kínema-ématos + gráphein, "escrita do movimento"), encontra-se materializada no vídeo e na televisão, mais do que no cinema propriamente dito." (Machado 1993)

A conclusão de Machado é polêmica. $\mathrm{E}$, analisada com rigor, demonstra toda a sua pressa metodológica. Ao afirmar que "em cada fração de tempo não existe propriamente uma imagem na tela, mas um único pixel, um ponto elementar de informação de luz", Machado faz uma confusão (deliberada?) entre o tempo/ movimento objetivo da tecnologia, ou seja, o que é medido por instrumentos de precisão, e o tempo/movimento percebido pelo espectador, que é limitado pelo órgão humano da visão. Machado também 
"esquece" que a ilusão de movimento do cinema, gerada pela projeção de 24 fotografias (ou "fotogramas") por segundo, tem o seu equivalente no vídeo, que pratica o mesmo ilusionismo com 30 "frames" por segundo. Em outras palavras, para quem assiste TV ou vídeo, não importa se a imagem eletrônica é um "conjunto de linhas sobrepostas", pois essas linhas não podem ser vistas individualmente, e muito menos cada um dos pontos que as compõem. $O$ telespectador vê apenas o fluxo de frames, assim como o espectador de cinema vê o fluxo de fotogramas.

É possível, no cinema, com um equipamento adequado (uma moviola, por exemplo), deter esse contínuo e ver um fotograma individualmente, pelo tempo que for desejado. O que veremos então? O que Machado chama, desta vez apropriadamente, de "ocupação da topografia de um quadro". Vemos o tempo "congelado", e, se o obturador da câmara estava na posição normal, a captação de um eventual movimento será semelhante a de uma foto feita com 1/50s de tempo de exposição.

O que acontece quando apertamos o botão de "pausa" num videocassete que está exibindo uma fita de vídeo prégravada? A fita pára de se movimentar e um cabeçote especial começa a girar sobre o mesmo ponto da fita, "Iendo" sempre o mesmo frame. Estamos, mais uma vez, congelando a imagem, só que, desta vez, temos 30 quadros por segundo da mesma imagem. Poderíamos, assim, se quiséssemos polemizar com Machado, dizer que o vídeo nos dá uma "ilusão de congelamento", enquanto no cinema o congelamento é de verdade. Mas isso é detalhe. $\mathrm{O}$ importante é perceber que tanto vídeo quanto cinema trabalham com a mesma limitação da visão humana, com o objetivo de mentir.

Mais tarde, ao fornecer exemplos dessa nova inscrição do tempo proporcionada pela televisão e pelo vídeo, Machado cita vários trabalhos experimentais e de videoarte, quase todos não-narrativos, e acaba dando ao vídeo um lugar absolutamente distante do cinema. Mas se refizermos nossas perguntas básicas - quais são os novos significantes do vídeo ou qual é a nova gramática do vídeo? -, as respostas de Machado tendem a ser vazias e quase desprovidas de interesse, à medida que prefere (como muitos outros acadêmicos) ignorar a concretude do espetáculo audiovisual para procurar em detalhes tecnológicos (no caso, ainda discutíveis) sustentação para teses vazias, pelo menos no campo de nosso estudo, a narrativa audiovisual. As conclusões de Machado podem ter valor no campo das artes plásticas e das videoinstalações, mas naufragam na pragmática do discurso audiovisual.

\section{Damasceno Ferreira e o fasma cinemático}

$\mathrm{Na}$ visão do professor Damasceno Ferreira ${ }^{4}$ a humanidade corre atrás de 3 "efes": a fome, a "foda" e o fasma. No âmbito deste trabalho, não abordaremos os dois primeiros, mas o terceiro "f" nos interessa, e muito. O fasma é a representação da realidade, o ato de "contar uma história", considerando o verbo "contar" e o substantivo "história" em suas acepções mais amplas. Quando se fala em cinema, estamos falando de uma das maneiras do ser humano criar seus fasmas, que nasceram em volta de uma fogueira, em eras pré-históricas, através de relatos de sonhos, e sofisticaram-se pelo uso posterior de desenhos, de falas e de textos escritos. A história da cultura humana é a história da produção dos fasmas.

A palavra "fasma", conforme a teoria enunciada por Damasceno Ferreira, deriva do grego "phásma", que significa simulacro, aparência. Em português, o Dicionário Aurélio oferece como opções a palavras "fasmato" ou "fasmo. Talvez a semiótica apresente a palavra "representação" como um bom substituto para "fasma". Aristóteles, 
em sua Poética, prefere simplesmente "imitação". Em qualquer dos casos, perderse-ia a relação com os dois outros "efes", que dão ao "fasma" o necessário senso de urgência e primitividade.

No cinema, explica Damasceno Ferreira, o verdadeiro e primitivo fasma é A chegada do trem na estação (irmãos Lumiére, 1895), que equivale ao vôo do 14Bis pilotado por Santos Dumont. Assim, podemos dizer que qualquer nave espacial, chegando aos confins do sistema solar, nada mais é que um 14Bis incrementado, enquanto a última experiência digital no campo da cinematografia nada mais é que um desdobramento óbvio daquele trem chegando à estação. O homem sempre quis voar, assim como sempre quis ver a realidade manipulada à sua frente de forma realista. A aviação e o cinema supriram esses desejos pela primeira vez. É natural que hoje haja outras formas, mais espetaculares para supri-los, mas nada de essencial mudou. O que, contudo, não diminui a dificuldade de estudar o fasma cinemático e tentar ver como esse fasma se articula na realização de um filme ou de qualquer outra obra audiovisual.

Só pode-se conceber o cinema como um processo em movimento, ou um processo de coordenação de vários movimentos. Ver o cinema pelas suas "partes" (e apenas por elas) é vê-lo de forma muito limitada. Assim, o "cronoema" é a unidade mínima da linguagem cinematográfica defendida por Damasceno Ferreira, por alusão ao fonema. A letra não é a unidade mínima da língua, e o plano não é a unidade mínima do cinema. Um cronoema seria um conjunto de imagens em movimento, limitadas pelo enquadramento da câmara, e inscritas dentro de um determinado tempo, limitado pelos cortes inicial e final.

O que nos leva às noções fundamentais de enquadramento e corte. O enquadramento, ensina Damasceno Ferreira, é o ente cinematográfico por excelência, mas existia muito antes da pintura, da fotografia ou do cinema. Pode-se falar em "enquadramento epistemológico", ou seja, a maneira como se recorta determinado tema, ou a maneira de olhar determinado assunto, para melhor conhecê-lo. Mas é no cinema que o enquadramento ganha um significado bem concreto e pode ser geometricamente representado.

O enquadramento é constituído por "plano" e "ângulo", que são categorias cinematográficas. O "plano" depende da distância entre câmara e plano filmado e do ângulo visual da objetiva empregada, enquanto o "ângulo" é determinado pela maneira como o cineasta coloca a câmara em relação a uma linha imaginária que parte, em linha reta e à frente, do "nariz metafísico" da pessoa ou objeto que está sendo filmado.

O "corte" é a essência do processo conhecido como montagem cinematográfica. Através do corte, realizado em etapa posterior à filmagem, o cineasta toma uma série de decisões, conforme explica o montador Giba Assis Brasil (2000):

"Podemos considerar a existência de quatro elementos na montagem de cinema, sendo cada um deles associado a uma característica dos planos e simultaneamente a uma característica do filme como um todo - e, de certa forma, também a um procedimento da montagem:

(a) Ordenação dos planos, isto é, a sua colocação em seqüência de forma a constituir significado. Começa a ser feita na decupagem, quando se prevê onde vai ocorrer cada corte. A ordenação dos planos está diretamente relacionada com a Narrativa do filme.

(b) Escolha dos planos, que pode ser a escolha da melhor tomada de cada plano decupado e rodado, mas também a escolha realizada já na decupa-gem: como mostrar cada 
pedaço da historinha a ser filmada. A escolha dos planos está relacionada com a Ênfase do filme.

(c) Duração dos planos (quando cortar), também prevista na decupagem e esboçada na filmagem, mas definida apenas na montagem. A duração de cada plano tem a ver com o Ritmo do filme.

(d) a Ligação entre os planos (em francês: Raccord), elemento fundamental da montagem, e que realmente não existe antes dela. A sucessão dos raccords determina a Fluência do filme. ${ }^{5}$

Para Damasceno Ferreira, enquadramento e corte são os elementos constituintes do fasma cinemático (ou audiovisual). Levando esta reflexão mais adiante, poderíamos dizer que uma nova linguagem audiovisual seria aquela que, embora lidando com as mesmas matériasprimas do cinema (imagens em movimento e sons sincronizados), utilizasse outros elementos expressivos, outros elementos constitutivos, de modo a criar um novo fasma, que seria um fasma "televisivo", ou "videográfico", ou "digital".

Ora, analisando os produtos e os processos descritos por Parente, Couchot e Machado, ainda não encontramos nada que se afaste, com a radicalidade mínima, dos conceitos fundadores de enquadramento e corte propostos por Damasceno Ferreira. O que não significa que não haja novidades no setor. Para situar corretamente estas novidades - e assim estudar os fenômenos de uma perspectiva menos enganadora -, Damasceno Ferreira propõe o conceito de "circunstância do espetáculo", de certo modo similar ao que Hjelmslev chama de "fatos não-lingüísticos".

Os espectadores de um filme (que estão numa sala de cinema), de um programa de TV ou de um vídeo (que estão em suas casas, na frente de uma TV ou de um telão) ou de uma animação digital transmitida via internet (que estão em suas casas ou em seus escritórios, na frente do monitor de um computador) estariam, todos, consumindo fasmas cinemáticos, mas em circunstâncias de espetáculo muito diversas, o que pode trazer diferentes percepções dos produtos, mas não altera a estrutura da linguagem que os constitui.

\section{Conclusão}

É preciso ter cuidado ao descrever a influência da era digital na narrativa cinematográfica. No âmbito deste artigo, vimos que três autores - Parente, Couchot e Machado - não hesitam em proclamar a revolução e declarar que as novas tecnologias não só abalaram os alicerces da tradição que estava estabelecida como ergueram um novo paradigma. Entretanto, basta confrontar estes autores (que não são cineastas) com algumas reflexões mais empíricas - enunciadas por Damasceno Ferreira, que atua no campo teórico, mas também é realizador de grande experiência - para que este novo paradigma não pareça tão novo assim.

Não se trata de temer o novo, e sim de vê-lo em sua verdadeira grandeza, em seu verdadeiro potencial destruidor do que existe e fundador do que existirá. Também não se trata de negar a qualidade artística e o potencial mercadológico de produtos audiovisuais que exploram os limites extremos da linguagem, experimentando a tridimensionalidade, propondo a interatividade, desconstruindo a narrativa tradicional, em busca de novos tempos e espaços, à procura de novas realidades. Muito devemos a estes visionários e a seus sonhos (concretizados ou não).

Mas, por enquanto, é forçoso dizer que nada de realmente "revolucionário" apareceu. A turba está nas ruas, a agitação é grande, mas ainda não caiu a Bastilha do velho fasma cinemático, construído com enquadramento e corte. Talvez, quando a Bastilha cair, choremos, em suas ruínas, em nome dos filmes nunca feitos, das histórias 
nunca contadas. Mas isso é improvável. A turba deve destruir apenas os afrescos e arranhar a pintura do edifício real, ou quem sabe explodir uma Bastilha simbólica, um simulacro de tradição, permanecendo, muito sólida, a estrutura narrativa que Aristóteles descreveu no século quarto a. C. Só teremos uma alteração significativa do "fasma" quando também mudarem significativamente os outros dois "efes" da existência humana .

\section{Notas}

1 PARENTE, André. "Os paradoxos da imagem-máquina", in Imagem-Máquina: a era das tecnologias do virtual, André Parente (org.). Rio de Janeiro, Editora 34, 1993, pp. 27-28.

2 COUCHOT, Edmond. "Da representação à simulação: evolução das técnicas e das artes da figuração", in Imagem-Máquina: a era das tecnologias do virtual, André Parente (org.). Rio de Janeiro, Editora 34, 1993, pp. 41-43.

3 MACHADO, Arlindo. "Anamorfoses cronotópicas ou a quarta dimensão da imagem", in Imagem-Máquina: a era das tecnologias do virtual, André Parente (org.). Rio de Janeiro, Editora 34, 1993. p. 76.

4 DAMASCENO FERREIRA, Aníbal. Entrevista concedida em Porto Alegre, agosto de 2000.

5 ASSIS BRASIL, Gilberto. Polígrafo da disciplina de Fundamentos de Cinema. Porto Alegre, 2000. 